\title{
Impact of Pulmonary Rehabilitation in Subjects With Mild COPD
}

\author{
Cristina Jácome MSc and Alda Marques PhD
}

\begin{abstract}
BACKGROUND: Pulmonary rehabilitation (PR) is a core component of the management of patients with moderate-to-very-severe COPD. However, as impairments in quadriceps muscle strength and health-related quality of life (HRQOL) are already present in patients with mild COPD, there is a need to investigate whether PR could also be beneficial to these patients. Thus, this study assessed the impact of PR on patients with mild COPD. METHODS: A quasi-experimental study was conducted. Twenty-six participants $\left(67.8 \pm 10.3\right.$ years old; $\mathrm{FEV}_{1} 83.8 \pm 6.4 \%$ of predicted) enrolled in a 12-week PR program with exercise training and psychoeducation. Lung function was assessed by spirometry, dyspnea with the Modified Medical Research Council questionnaire, functional balance with the Timed Up and Go test, muscle strength with 10-repetition maximum testing, exercise tolerance with the 6-min walk test, emotional state with the Depression Anxiety Stress Scales, and HRQOL with the St George Respiratory Questionnaire (SGRQ). RESULTS: Significant effects were observed on participants' dyspnea $(P=.003$, effect size $[\mathrm{ES}]=0.7)$, functional balance $(P<.001, \mathrm{ES}=0.8)$, shoulder flexor/knee extensor strength $(P<.001, \mathrm{ES}=1.2-1.3)$, and exercise tolerance $(P<.001$, ES $=0.5)$. With the exception of the SGRQ impact score, the symptom $(P<.001, \mathrm{ES}=0.6)$, activity $(P=.02, \mathrm{ES}=0.4)$, and total $(P=.005, \mathrm{ES}=0.3)$ scores improved significantly after PR. The PR program had no significant effect on participants' lung function and emotional state. CONCLUSIONS: Patients with mild COPD benefit from PR and could therefore be routinely included in these programs. Studies with more robust designs and with long-term follow-ups are needed to inform guidelines for PR in mild COPD. Key words: chronic obstructive pulmonary disease; COPD; pulmonary rehabilitation; early medical intervention. [Respir Care 2014;59(10):1577-1582. ( 2014 Daedalus Enterprises]
\end{abstract}

\section{Introduction}

Pulmonary rehabilitation (PR) is "a comprehensive intervention based on a thorough patient assessment followed by patient-tailored therapies which include, but are not limited to, exercise training, education, and behavior change, designed to improve the physical and psycholog-

\footnotetext{
Both authors are affiliated with the School of Health Sciences, University of Aveiro, Aveiro, Portugal. Ms Jácome is also affiliated with the Research Centre in Physical Activity, Health and Leisure, Faculty of Sports, University of Porto, Porto, Portugal. Dr Marques is also affiliated with the Unidade de Investigação e Formação sobre Adultos e Idosos, Porto, Portugal.
}

This work was funded by Portuguese national funds through Foundation for Science and Technology (Fundação para a Ciência e a Tecnologia) Project SFRH/BD/84665/2012.

The authors have disclosed no conflicts of interest. ical condition of people with chronic respiratory disease."1 A meta-analysis demonstrated that PR is effective in improving dyspnea and health-related quality of life (HRQOL) in patients with moderate-to-very-severe COPD, ${ }^{2}$ and thus, it is currently recognized as a core component of the management of these patients. ${ }^{3}$

Recent evidence showed that quadriceps muscle strength and HRQOL are already impaired in patients with mild COPD (post-bronchodilator $\mathrm{FEV}_{1} / \mathrm{FVC}<0.7$ and $\mathrm{FEV}_{1}$ $>80 \%$ of predicted). ${ }^{4,5}$ Therefore, as stated in the American Thoracic Society/European Respiratory Society state-

\footnotetext{
Correspondence: Alda Marques PhD, School of Health Sciences, University of Aveiro (ESSUA), Campus Universitário de Santiago, Agras do Crasto, Edifício 30, 3810-193 Aveiro, Portugal. E-mail: amarques@ua.pt.
}

DOI: $10.4187 /$ respcare.03091 
ment on PR, there is a need to investigate the potential of PR in these patients. ${ }^{1}$

A preliminary study by Riario-Sforza et $\mathrm{al}^{6}$ found that, after a 6-week out-patient PR program, patients with mild COPD improved their exercise tolerance. However, the effects of PR on other health domains have not yet been established. Thus, this study aimed to assess the impact of PR on the lung function, dyspnea, functional balance, muscle strength, exercise tolerance, emotional state, and HRQOL of patients with mild COPD. In line with research conducted on more severe grades of COPD, it is hypothesized that patients with mild COPD will also benefit from PR and that these benefits will be observed in different health domains.

\section{Methods}

\section{Design and Participants}

A quasi-experimental one-group pretest-posttest design was used. Out-patients with mild COPD were recruited from 2 primary care centers. Inclusion criteria were diagnosis of mild COPD according to the Global Initiative for Chronic Obstructive Lung Disease (GOLD) criteria (postbronchodilator $\mathrm{FEV}_{1} / \mathrm{FVC}<0.7$ and $\mathrm{FEV}_{1}>80 \%$ of predicted), $\geq 18$ years old, and clinical stability for 1 month prior to the study (ie, no hospital admissions or exacerbations as defined by GOLD). ${ }^{4}$ Patients were excluded if they presented severe psychiatric, neurologic, or musculoskeletal conditions ${ }^{7}$ and/or unstable cardiovascular disease that could interfere with their performance during the exercise training sessions. The study received full approval from the institutional ethics committee, and written informed consent was obtained before data collection.

\section{Intervention}

A 12-week PR program with exercise training (3 sessions/week, $60 \mathrm{~min}$ each) and psychoeducation (one session/week, $90 \mathrm{~min}$ ) was conducted. The exercise training sessions were composed of:

1. A warm-up and a cool-down period including rangeof-motion, stretching, low-intensity aerobic exercises and breathing techniques $(5-10 \mathrm{~min}){ }^{8}$

2. Endurance training (walking) at $60-80 \%$ of the average speed achieved during the 6-min walk test (6MWT; $20 \mathrm{~min}) .{ }^{9}$ The training intensity was adjusted according to the patient's symptoms on the modified Borg scale (a rating of 4-6 on perceived dyspnea/fatigue was an indicator of adequate training intensity). ${ }^{1}$

3. Strength training including 7 exercises ( 2 sets of 10 repetitions) of the major upper and lower limb muscle groups using free weights and ankle weights (15 min). ${ }^{10}$

\section{QUICK LOOK}

\section{Current knowledge}

Pulmonary rehabilitation (PR) is a comprehensive intervention that includes education, training, and behavior modification aimed at improving quality of life in patients with chronic respiratory disease. PR has been shown to be effective in reducing dyspnea and improving health-related quality of life in patients with moderate-to-severe COPD.

\section{What this paper contributes to our knowledge}

In a small group of subjects with mild COPD, a 12week PR program reduced dyspnea and improved muscle strength, and exercise tolerance. There was no impact on lung function or psychological well-being. PR for mild COPD provides benefits that require further study.

The amount of weight was between 50 and $85 \%$ of the 10-repetition maximum (10-RM). ${ }^{1}$ The training progression was based on the two-for-two rule (load was increased when 2 additional repetitions could be performed on 2 consecutive sessions $)^{10}$ and on the patient's symptoms (modified Borg Scale 4-6). ${ }^{1}$

4. Balance training consisting of static and dynamic exercises using upright positions (5 min).

In the psychoeducation component, the main themes addressed were information about COPD, medication management, healthy lifestyles, falls and their prevention, emotion-management strategies, and community resources.

\section{Data Collection}

Sociodemographic and clinical (smoking habits, body mass index, exacerbations in the past 3 months) data were obtained to characterize the sample. Data on lung function, dyspnea, functional balance, muscle strength, exercise tolerance, emotional state, and HRQOL were collected before and after the PR program. All questionnaires/tests were administered in a standardized order.

\section{Outcome Measures}

Lung Function. A spirometric test using a portable spirometer (MicroLab 3500, CareFusion, San Diego, California) was performed according to standardized guidelines. ${ }^{11}$

Dyspnea. Patients reported their activity limitations resulting from dyspnea by selecting the statement from the 


\section{Pulmonary Rehabilitation in Subjects With Mild COPD}

Modified Medical Research Council questionnaire that best described their limitations. ${ }^{4}$ The questionnaire comprises 5 grades (statements) on a scale from 0 to 4 , with higher grades indicating greater perceived respiratory limitation. This scale is simple and valid to characterize the impact that dyspnea has on activities of patients with COPD, ${ }^{4}$ and variations of one point indicate a perceived clinical improvement. ${ }^{12}$

Functional Balance. The Timed Up and Go test was used to assess functional balance. ${ }^{13}$ The test requires the patient to rise from a standard chair, walk $3 \mathrm{~m}$, turn around, walk back to the chair, and sit down. Patients were instructed to walk quickly but as safely as possible. Two tests were performed, and the best performance was considered.

Muscle Strength. The muscle strength of the shoulder flexors and of the knee extensors of the dominant limbs was assessed using the 10-RM with ankle and free weights. In patients with COPD, the completion of 1-RM testing may not be advisable or safe ${ }^{14}$; thus, 10-RM has been used. ${ }^{15}$ The 10-RM was considered the maximum amount of weight that could be moved through the full range of motion 10 times with the proper technique and without compensatory movements. ${ }^{10}$

Exercise Tolerance. Exercise tolerance was measured using the 6MWT. The measurement properties of this test are well established in COPD, and it has showed a similar peak rate of oxygen uptake and heart rate as an incremental cycle ergometer test. ${ }^{16}$ Two tests were performed according to the protocol described by the American Thoracic Society, ${ }^{17}$ and the best performance was considered. The minimum clinically important difference for the 6MWT is $25 \mathrm{~m}$ in patients with COPD. ${ }^{18}$

Emotional State. The Depression Anxiety Stress Scales (DASS) measure the negative emotional states of depression, anxiety, and stress. ${ }^{19}$ Each subscale has 7 items, and the participant is asked to use a 4-point (from 0 to 3 ) severity scale to rate the extent to which they have experienced each state over the past week. Internal consistency has been shown to be acceptable for all 3 scales (Cronbach's alpha statistics between 0.82 and 0.93). ${ }^{20}$ Consistent with convention, during the statistical analysis, all DASS-21 scores were doubled. This procedure facilitates comparison with normative values established for DASS42. The maximum score of DASS- 42 is 42 in each of the depression, anxiety and stress scales, and higher scores indicate high levels of emotional distress.

HRQOL. The St George Respiratory Questionnaire (SGRQ) is a disease-specific instrument designed to mea- sure quality of life in patients with chronic lung disease. ${ }^{21}$ The questionnaire has 3 domains: symptoms, activities, and impact. SGRQ presented high internal consistency with Cronbach's alpha statistics $(>0.7$ in the subdomains and $>0.9$ in the overall questionnaire). ${ }^{22}$ For each domain and for the total questionnaire, the score ranges from 0 (no impairment) to 100 (maximum impairment). A change of 4 units is considered clinically relevant. ${ }^{21}$

\section{Statistical Analysis}

Using 6MWT data from the study of Riario-Sforza et al ${ }^{6}$ (effect size $[\mathrm{ES}]=0.88$ ), a sample size estimation with $95 \%$ power $(\alpha=0.05)$ was performed. This power analysis determined that a statistically significant difference in the 6MWT after a PR program would be detected with 19 subjects. As PR programs have considerable dropout rates, varying between 20 and $40 \%, 23,2430$ patients were recruited.

Descriptive statistics were used to describe the sample. For each outcome measure, the normality of the data was investigated with the Shapiro-Wilk test. Paired $t$ tests for normally distributed data and Wilcoxon signed-rank tests for ordinal/non-normally distributed data were used to compare pre- and post-PR variables. The level of significance was set at 0.05 . These analyses were performed using IBM SPSS Statistics 20.0 (IBM Corporation, Armonk, New York).

Statistical analysis was completed with the estimation of ES indices, which evaluate the magnitude of treatment effect. ${ }^{25}$ The formula Cohen's dz was used (mean change score divided by the SD of change), as this is the ES index recommended for matched pairs. ${ }^{26}$ Cohen's $\mathrm{dz}$ for each outcome measure was calculated using the G*Power 3 software (University Düsseldorf, Düsseldorf, Germany) and was interpreted as a small ( $\geq 0.2)$, medium ( $\geq 0.5)$, or large $(\geq 0.8)$ effect. ${ }^{27}$

\section{Results}

Thirty patients enrolled in the study; however, 4 (13.3\%) dropped out due to overlap between the program schedule and professional activities $(n=1)$, relocation $(n=1)$, respiratory exacerbation $(n=1)$, and no reason given $(n=$ 1). Therefore, 26 participants (16 males, $67.8 \pm 10.3$ years old) completed the study. Table 1 provides the characteristics of the participants.

The PR program had no effect on lung function (pre $83.8 \%$ of predicted vs post $84.1 \%$ of predicted, $P=.73$ ) (Table 2). A reduction in participants' dyspnea was observed (pre median [interquartile range] 1 [1-2] vs post 1 $[0-1], P=.003$, ES $=0.7)$, with more than half of the participants $(n=16,61.5 \%)$ presenting a Modified Medical Research Council scale variation $>1$. Significant im- 
Table 1. Sociodemographic and Clinical Characteristics of Participants

\begin{tabular}{|c|c|}
\hline Characteristics & Result \\
\hline Age, mean $\pm \mathrm{SD}$ years & $67.8 \pm 10.3$ \\
\hline Male, $n(\%)$ & $16(59.3)$ \\
\hline $\mathrm{BMI}$, mean $\pm \mathrm{SD} \mathrm{kg} / \mathrm{m}^{2}$ & $28.7 \pm 5.0$ \\
\hline Smokers, $n(\%)$ & $7(25.9)$ \\
\hline \multicolumn{2}{|l|}{ Exacerbations past 3 months, $n(\%)$} \\
\hline 0 & $14(53.9)$ \\
\hline $1-2$ & 7 (26.9) \\
\hline$\geq 3$ & $5(19.2)$ \\
\hline $\mathrm{FEV}_{1}$, mean $\pm \mathrm{SD} \mathrm{L}$ & $2 \pm 0.4$ \\
\hline $\mathrm{FEV}_{1}$, mean $\pm \mathrm{SD} \%$ of predicted & $83.8 \pm 6.4$ \\
\hline \multicolumn{2}{|l|}{$n=26$} \\
\hline $\mathrm{BMI}=$ body mass index & \\
\hline
\end{tabular}

provements were also verified in functional balance (pre $7.8 \mathrm{~s}$ vs post $6.7 \mathrm{~s}, P<.001$ ), muscle strength (shoulder flexors pre $2.3 \mathrm{~kg}$ vs post $3.6 \mathrm{~kg}$, knee extensors pre $4.1 \mathrm{~kg}$ vs post $6.7 \mathrm{~kg}, P<.001$ ), and exercise tolerance (pre $432 \mathrm{~m}$ vs post $464 \mathrm{~m}, P<.001$ ), with medium and large ES values (from 0.5 to 1.3 ) (Table 2). However, no differences were found for the emotional states of depression (pre median 6 vs post 4, $P=.65$ ), anxiety (pre median 6 vs post $5, P=.82$ ), and stress (pre median 10 vs post 8 , $P=.63$ ). The SGRQ total score (pre 31.3 vs post 25 , $P=.005, \mathrm{ES}=0.3$ ), SGRQ symptom score (pre $46.3 \mathrm{vs}$ post $34.7, P<.001$, ES $=0.6$ ), and SGRQ activity score (pre 44 vs post $34.8, P=.02, \mathrm{ES}=0.4$ ) improved significantly after PR, reaching the minimum clinically important difference (4 units). ${ }^{21}$ However, there was no significant improvement in the SGRQ impact score (pre 19.4 vs post $16.3, P=.14$ ).

\section{Discussion}

According to our knowledge, this was the first study to investigate the effects of PR on different health domains in patients with mild COPD. The main finding was that a 12-week PR program was effective in improving subjects' dyspnea, functional balance, muscle strength, exercise tolerance, and HRQOL.

A perceived clinical improvement in dyspnea was observed in $>50 \%$ of the patients, in line with the existing evidence on the benefits of PR in patients with moderateto-very-severe COPD. ${ }^{12}$ This result demonstrates that patients with mild COPD already experience restrictions in their daily life due to dyspnea and that PR has the potential to reverse this situation. Regarding the effect of the program on subjects' functional balance, a change of $-1.1 \pm 1 \mathrm{~s}$ in the Timed Up and Go score was found. This change is lower than that obtained by Beauchamp et al ${ }^{28}$
Table 2. Effect of PR on Lung Function, Dyspnea, Functional Balance, Muscle Strength, Exercise Tolerance, Emotional State, and Health-Related Quality of Life

\begin{tabular}{|c|c|c|c|c|}
\hline Variable & Pre-PR & Post-PR & $P$ & $\mathrm{ES}$ \\
\hline $\begin{array}{l}\mathrm{FEV}_{1} \text {, mean } \pm \mathrm{SD} \% \text { of } \\
\text { predicted }\end{array}$ & $83.8 \pm 6.4$ & $84.1 \pm 5.4$ & $.73 \dagger$ & 0 \\
\hline $\begin{array}{l}\text { MMRC questionnaire score } \\
\text { (median [interquartile } \\
\text { range]) }\end{array}$ & $1(1-2)$ & $1(0-1)$ & $.003+$ & 0.7 \\
\hline TUG score, mean $\pm \mathrm{SD} s$ & $7.8 \pm 1.5$ & $6.7 \pm 1.2$ & $<.001 \dagger$ & 0.8 \\
\hline $\begin{array}{l}\text { 10-RM shoulder flexor } \\
\text { strength, mean } \pm \mathrm{SD} \mathrm{kg}\end{array}$ & $2.3 \pm 0.9$ & $3.6 \pm 1.2$ & $<.001 \dagger$ & 1.2 \\
\hline $\begin{array}{l}\text { 10-RM knee extensor } \\
\text { strength, mean } \pm \mathrm{SD} \mathrm{kg}\end{array}$ & $4.1 \pm 2.1$ & $6.7 \pm 1.9$ & $<.001 \dagger$ & 1.3 \\
\hline $6 \mathrm{MWD}$, mean $\pm \mathrm{SD} \mathrm{m}$ & $432 \pm 76$ & $464 \pm 76$ & $<.001 \dagger$ & 0.5 \\
\hline \multicolumn{5}{|l|}{$\begin{array}{l}\text { DASS score (median } \\
\quad \text { [interquartile range]) }\end{array}$} \\
\hline Depression & $6(1.5-9)$ & $4(0.5-8)$ & $.65 \ddagger$ & 0.2 \\
\hline Anxiety & $6(1.5-12)$ & $5(2-10)$ & $.82 \neq$ & 0 \\
\hline Stress & $10(5.5-16)$ & $8(4-15)$ & $.63 \ddagger$ & 0 \\
\hline \multicolumn{5}{|l|}{$\mathrm{SGRQ}$, mean $\pm \mathrm{SD}$} \\
\hline Total score & $31.3 \pm 18.5$ & $25 \pm 17.8$ & $.005 \dagger$ & 0.3 \\
\hline Symptom score & $46.3 \pm 20.2$ & $34.7 \pm 21.4$ & $<.001 \dagger$ & 0.6 \\
\hline Activity score & $44 \pm 25.2$ & $34.8 \pm 24.3$ & $.02 \dagger$ & 0.4 \\
\hline Impact score & $19.4 \pm 17.9$ & $16.3 \pm 15.4$ & $.14 \dagger$ & 0.2 \\
\hline $\begin{array}{l}n=26 \\
\dagger \text { Paired } t \text { test } \\
\ddagger \text { Wilcoxon signed-rank test } \\
\text { PR }=\text { pulmonary rehabilitation } \\
\mathrm{ES}=\text { effect size } \\
\text { MMRC = Modified Medical Research } \\
\text { TUG }=\text { Timed Up and Go } \\
\text { 10-RM = 10-repetition maximum } \\
6 \mathrm{MWD}=6 \text {-min walking distance } \\
\text { DASS }=\text { Depression Anxiety and Stress } \\
\text { SGRQ }=\text { St George Respiratory Questio }\end{array}$ & $\begin{array}{l}\text { Scales } \\
\text { nnaire. }\end{array}$ & & & \\
\hline
\end{tabular}

$(-1.5 \pm 2.4 \mathrm{~s})$, who examined the effect of a standard PR program on the balance of patients with more severe COPD grades (mean $\mathrm{FEV}_{1} 46.3 \pm 22.3 \%$ ). However, this result is not surprising since subjects with mild COPD had better baseline scores compared with patients included in the previously mentioned study, and thus, less potential to further improve their functional balance was expected. Respective increases of 56.5 and $63.4 \%$ in shoulder flexor and knee extensor muscle strength were verified. These results are difficult to interpret in the absence of published information on minimum clinically important differences for the 10-RM. Nevertheless, the percentage changes found are similar to previous research (a $56.3 \%$ increase in chest pull exercise and $88.2 \%$ in leg extension). ${ }^{29}$

The improvement in the distance walked after PR was $\sim 32 \mathrm{~m}$. Considering that $25 \mathrm{~m}$ is the minimum clinically important difference for the 6MWT in patients with COPD, ${ }^{18}$ it could be assumed that this study achieved the clinically important effect. However, this minimum clinically important difference was established based on a sam- 


\section{Pulmonary Rehabilitation in Subjects With Mild COPD}

ple of patients with a wide range of disease severity and may not represent a clinically important effect for patients with mild COPD. Future studies should determine the minimum clinically important difference for the 6MWT in patients with mild COPD to contribute to clinical decision making in this COPD population.

An improvement in the SGRQ total score of $\sim 6$ units was also observed, exceeding the 4 units considered clinically relevant. ${ }^{21}$ This result demonstrates that HRQOL in patients with mild COPD, even if not severely affected (baseline scores of 31.3 in 100), can be improved with PR. Contrary to the symptom and activity domains, the impact domain was not significantly different after PR. Patients with mild COPD might not yet experience relevant disturbances in social and psychological functioning in their daily life, demonstrated by the low impact scores found at baseline (19.4 in 100), ${ }^{5}$ and therefore, this domain had less potential to be improved.

The PR program had no effect on lung function, which is in accordance with the short-term effects of PR. ${ }^{30}$ However, a longitudinal study of patients with moderate-tosevere COPD showed that, after $3 \mathrm{y}$, the decline in $\mathrm{FEV}_{1}$ was significantly lower in the PR group compared with the standard care group. ${ }^{31}$ The potential of PR in delaying the decline of lung function should therefore be examined in patients with mild COPD as well. Patients' emotional state also did not improve after the intervention. However, significant benefits in the emotional function of patients with moderate-to-very-severe COPD after PR programs have been described. ${ }^{2}$ Since subjects' baseline scores in DASS were only slightly higher than normative values (depression 6 vs 2, anxiety 6 vs 2 , stress 10 vs 8), ${ }^{20}$ one possible reason for this result may be that patients with mild COPD may not yet experience significant emotional distress.

The overall findings suggest that PR is effective in improving dyspnea, functional balance, muscle strength, exercise tolerance, and HRQOL in patients with mild COPD. Thus, the critical question for future studies should move from "should patients with mild COPD be integrated in PR?" to "how should PR be delivered to these patients?". Since patients are not referred to hospital-based PR programs until they have advanced COPD, ${ }^{1}$ less expensive and complex PR programs available at primary care centers could be a promising strategy to deliver PR to patients with mild COPD. Through the exercise training component, these programs would maintain patients at higher levels of function. Exercise programs in fitness centers with adequate supervision by trained professionals would probably accomplish the same physical benefits of these simple PR programs with fewer costs; however, these programs do not address patients' education and behavior change needs. Through collaborative self-management strategies, the psychoeducation component of PR increases patients' knowledge and skills, key aspects to optimally manage their disease. Therefore, the potential of primary care-based PR to modify the COPD trajectory in patients at earlier grades should be investigated in future COPD research.

This study has some limitations that need to be acknowledged. The absence of a control group is a limitation of this exploratory study. However, as no research has been conducted on this topic, this limitation does not appear to remove the validity and importance of the results found. In future studies, a control group of patients with similar sociodemographic and clinical characteristics should be included. A small sample size was estimated to be sufficient to detect statistically significant differences in the 6MWT; however, a larger sample would probably help detect statistically significant differences in the other outcome measures collected such as the DASS and SGRQ impact scores. Nonetheless, data from these outcome measures may inform the estimation of sample sizes in future studies. Moreover, the evaluators in this study were the same health professionals that delivered the PR program, which may have influenced the way that outcome measures were assessed. Due to the cross-sectional design, the long-term effects of PR on mild COPD could not be established. Blind randomized controlled trials with longterm follow-ups are therefore needed.

\section{Conclusion}

The PR program was effective in improving dyspnea, functional balance, muscle strength, exercise tolerance, and HRQOL in patients with mild COPD, suggesting that these patients would benefit from being routinely included in PR programs. Studies with more robust designs and with longterm follow-ups are needed to inform guidelines for PR in mild COPD.

\section{ACKNOWLEDGMENTS}

We are very grateful to Raquel Gabriel and Joana Cruz (School of Health Sciences, University of Aveiro, Aveiro, Portugal) for contributions to the implementation of the intervention and to Andreia Hall for statistical advice (Department of Mathematics, University of Aveiro).

\section{REFERENCES}

1. Spruit MA, Singh SJ, Garvey C, ZuWallack R, Nici L, Rochester C, et al. An official American Thoracic Society/European Respiratory Society statement: key concepts and advances in pulmonary rehabilitation. Am J Respir Crit Care Med 2013;188(8):e13-e64.

2. Lacasse Y, Goldstein R, Lasserson TJ, Martin S. Pulmonary rehabilitation for chronic obstructive pulmonary disease. Cochrane Database Syst Rev 2006;(4):CD003793.

3. Martín-Valero R, Cuesta-Vargas A, Labajos-Manzanares M. Review about clinical control trials of respiratory rehabilitation in chronic obstructive pulmonary disease. Rehabilitación. 2010;44(2):158-166.

4. Vestbo J, Hurd SS, Agustí AG, Jones PW, Vogelmeier C, Anzueto A, et al. Global strategy for the diagnosis, management, and preven- 


\section{Pulmonary Rehabilitation in Subjects With Mild COPD}

tion of chronic obstructive pulmonary disease. Am J Respir Crit Care Med 2013;187(4):347-365.

5. Shrikrishna D, Patel M, Tanner RJ, Seymour JM, Connolly BA, Puthucheary ZA, et al. Quadriceps wasting and physical inactivity in patients with COPD. Eur Respir J 2012;40(4):1115-1122.

6. Riario-Sforza GG, Incorvaia C, Paterniti F, Pessina L, Caligiuri R, Pravettoni $\mathrm{C}$, et al. Effects of pulmonary rehabilitation on exercise capacity in patients with COPD: a number needed to treat study. Int J Chron Obstruct Pulmon Dis 2009;4:315-319.

7. Nici L, ZuWallack R. Pulmonary rehabilitation: today and tomorrow. Breathe 2010;6(4):305-311.

8. Martín-Valero R, Cuesta-Vargas AI, Labajos-Manzanares MT. Types of physical exercise training for COPD patients. In: Ong DKC, editor. Chronic obstructive pulmonary disease-current concepts and practice. Rijeka, Croacia: InTech; 2012.

9. Jenkins SC. 6-Minute walk test in patients with COPD: clinical applications in pulmonary rehabilitation. Physiotherapy 2007;93(3): 175-182.

10. American College of Sports Medicine. ACSM's resource manual for guidelines for exercise testing and prescription. Philadelphia: Lippincott Williams \& Wilkins; 2009.

11. Miller MR, Hankinson J, Brusasco V, Burgos F, Casaburi R, Coates A, et al. Standardisation of spirometry. Eur Respir J 2005;26(2):319338.

12. de Torres JP, Pinto-Plata V, Ingenito E, Bagley P, Gray A, Berger R, Celli B. Power of outcome measurements to detect clinically significant changes in pulmonary rehabilitation of patients with COPD. Chest 2002;121(4):1092-1098.

13. Podsiadlo D, Richardson S. The timed "up and go": a test of basic functional mobility for frail elderly persons. J Am Geriatr Soc 1991; 39(2):142-148.

14. Lotshaw AM, Thompson M, Sadowsky HS, Hart MK, Millard MW. Quality of life and physical performance in land- and water-based pulmonary rehabilitation. J Cardiopulm Rehabil Prev 2007;27(4): 247-251.

15. Reynolds JM, Gordon TJ, Robergs RA. Prediction of one repetition maximum strength from multiple repetition maximum testing and anthropometry. J Strength Cond Res 2006;20(3):584-592.

16. Hill K, Dolmage TE, Woon L, Coutts D, Goldstein R, Brooks D. Comparing peak and submaximal cardiorespiratory responses during field walking tests with incremental cycle ergometry in COPD. Respirology 2012;17(2):278-284.

17. ATS Committee on Proficiency Standards for Clinical Pulmonary Function Laboratories. ATS statement: guidelines for the six-minute walk test. Am J Respir Crit Care Med 2002;166(1):111-117.

18. Holland AE, Hill CJ, Rasekaba T, Lee A, Naughton MT, McDonald CF. Updating the minimal important difference for six-minute walk distance in patients with chronic obstructive pulmonary disease. Arch Phys Med Rehabil 2010;91(2):221-225.

19. Moradipanah F, Mohammadi E, Mohammadil AZ. Effect of music on anxiety, stress, and depression levels in patients undergoing coronary angiography. East Mediterr Health J 2009;15(3):639-647.

20. Henry JD, Crawford JR. The short-form version of the Depression Anxiety Stress Scales (DASS-21): construct validity and normative data in a large non-clinical sample. Br J Clin Psychol 2005;44(Pt 2):227-239.

21. Jones PW. St. George's Respiratory Questionnaire: MCID. COPD 2005;2(1):75-79

22. Ferrer M, Villasante C, Alonso J, Sobradillo V, Gabriel R, Vilagut $\mathrm{G}$, et al. Interpretation of quality of life scores from the St George's Respiratory Questionnaire. Eur Respir J 2002;19(3):405-413.

23. Garrod R, Marshall J, Barley E, Jones PW. Predictors of success and failure in pulmonary rehabilitation. Eur Respir J 2006;27(4):788794

24. Fischer MJ, Scharloo M, Abbink JJ, van 't Hul AJ, van Ranst D, Rudolphus A, et al. Drop-out and attendance in pulmonary rehabilitation: the role of clinical and psychosocial variables. Respir Med 2009;103(10):1564-1571.

25. Kraemer HC, Kupfer DJ. Size of treatment effects and their importance to clinical research and practice. Biol Psychiatry 2006;59(11): 990-996.

26. Faul F, Erdfelder E, Lang AG, Buchner A. G*Power 3: a flexible statistical power analysis program for the social, behavioral, and biomedical sciences. Behav Res Methods 2007;39(2):175-191.

27. Cohen J. Statistical power analysis for the behavioral sciences. Hillsdale, NJ: Lawrence Erlbaum Associates; 1988.

28. Beauchamp MK, O'Hoski S, Goldstein RS, Brooks D. Effect of pulmonary rehabilitation on balance in persons with chronic obstructive pulmonary disease. Arch Phys Med Rehabil 2010;91(9):14601465.

29. Ortega F, Toral J, Cejudo P, Villagomez R, Sánchez H, Castillo J, Montemayor T. Comparison of effects of strength and endurance training in patients with chronic obstructive pulmonary disease. Am J Respir Crit Care Med 2002;166(5):669-674.

30. Zwick RH, Burghuber OC, Dovjak N, Hartl S, Kössler W, Lichtenschopf $\mathrm{A}$, et al. [The effect of one year outpatient pulmonary rehabilitation on patients with COPD]. Wien Klin Wochenschr 2009; 121(5-6):189-195. Article in German.

31. Stav D, Raz M, Shpirer I. Three years of pulmonary rehabilitation: inhibit the decline in airflow obstruction, improves exercise endurance time, and body-mass index, in chronic obstructive pulmonary disease. BMC Pulm Med 2009;9:26. 